\title{
Use of a Disposable Self-adhesive Grid for Accurate Microimplant Placement
}

\author{
${ }^{1}$ Bhagyashree S Jadhav, ${ }^{2}$ Vivek Patni, ${ }^{3}$ Priyanka Pawar
}

\begin{abstract}
Microimplants have ushered in the concept of absolute anchorage by intraoral means with the added benefit of being completely operator dependent. These factors ensure efficient anchorage control. However, these benefits come at the cost of precise placement considering the proximity of anatomically significant structures. It is of utmost importance to avoid damage to roots in case of interradicular placement. In order to overcome this difficulty, the following case report describes an innovative grid-guide template with an anti-inflammatory adhesive backing for accurate and easy microimplant placement. The assembly consists of a stainless steel grid mesh stuck on a micropore surgical tape with trioplast dental paste on the tissue-facing surface. It is an accurate, efficient, economical, and easy method of microimplant placement.
\end{abstract}

Keywords: Anchorage, Grid guide, Microimplant.

How to cite this article: Jadhav BS, Patni V, Pawar P. Use of a Disposable Self-adhesive Grid for Accurate Microimplant Placement. J Contemp Dent 2017;7(3):161-165.

Source of support: Nil

Conflict of interest: None

\section{INTRODUCTION}

Anchorage plays a major role in deciding the outcome of an orthodontic treatment. Anchorage consideration and anchorage preparation are one of the vital steps in orthodontic treatment planning. Traditional modalities for anchorage conservation utilized intraoral or extraoral sources. The intraoral sources made absolute anchorage difficult to attain, while the extraoral much depends on the patient's compliance to be effective. The use of microimplants made the dream of absolute intraoral anchorage a reality with the added advantage of being totally operator dependent. ${ }^{1-7}$

\footnotetext{
${ }^{1}$ Resident, ${ }^{2}$ Professor, ${ }^{3}$ Assistant Professor

1,2Department of Orthodontics and Dentofacial Orthopedics Mahatma Gandhi Mission's Dental College and Hospital, Navi Mumbai, Maharashtra, India

${ }^{3}$ Department of Orthodontics and Dentofacial Orthopedics Triveni Institute of Dental Sciences, Hospital \& Research Centre Bilaspur, Chhattisgarh, India

Corresponding Author: Bhagyashree S Jadhav, Resident Department of Orthodontics and Dentofacial Orthopedics Mahatma Gandhi Mission's Dental College and Hospital, Navi Mumbai, Maharashtra, India, Phone: +919773202600, e-mail: bsjadhav89@gmail.com
}

Microimplants are available in a variety of sizes and shapes. They can be used in different sites in the oral cavity for their required purpose. Their small size facilitates utilization in interradicular areas, thus expanding the horizon of their use. Microimplants also offer the advantage of being immediately loaded. The crucial factor to be taken into consideration with regard to their placement is the proximity of the surrounding anatomic structures. There is a possibility of damage to the roots, if placement site is interradicular. ${ }^{8}$ Placement of a microimplant in close approximation of the root can result in insufficient bone remodeling around the screw and transmission of the occlusal forces through the teeth to the screw, which can lead to implant failure. ${ }^{9}$

There have been numerous implant placement guides described in the literature. ${ }^{10-20}$ The shortcomings of these methods are that they are cumbersome and fabrication involves complicated soldering procedures, difficulty in stabilizing during radiographic process, poor tissue adaptation to the placement site, giving magnification errors or parallax errors in the radiograph, increased chairside time, and the need to sterilize after each use.

The present article describes a metal grid-guide with an adhesive base for accurate placement of microimplant. The guide has been fabricated with the help of easily available armamentarium. It can be prefabricated and stored in sterilized conditions for use in a patient and is discarded after use. This innovation helps precise placement with reduction in chairside time of microimplant placement.

\section{CASE REPORT}

A 20-year-old female patient reported to the Department of Orthodontics and Dentofacial Orthopedics with the chief complaint of forwardly placed upper front teeth. On diagnosis, the patient had a skeletal Class II maxillomandibular relationship with prognathic maxilla and retrognathic mandible with an anticlockwise rotational tendency, an Angle's Class I molar, and Class I canine relationship bilaterally, with proclination and protrusion of maxillary and mandibular anteriors, crossbite with 44 , a convex soft tissue profile, an acute nasolabial angle, and protrusive lower lip. The treatment plan included extraction of all first premolars followed by levelling and alignment of the teeth. Retraction of the anteriors was 


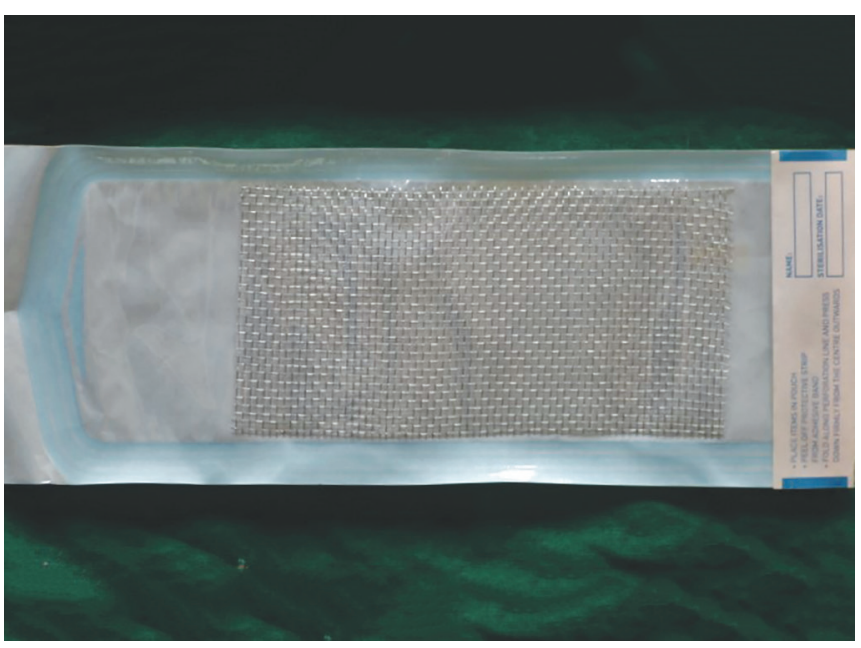

Fig. 1: Autoclaved stainless steel wire mesh

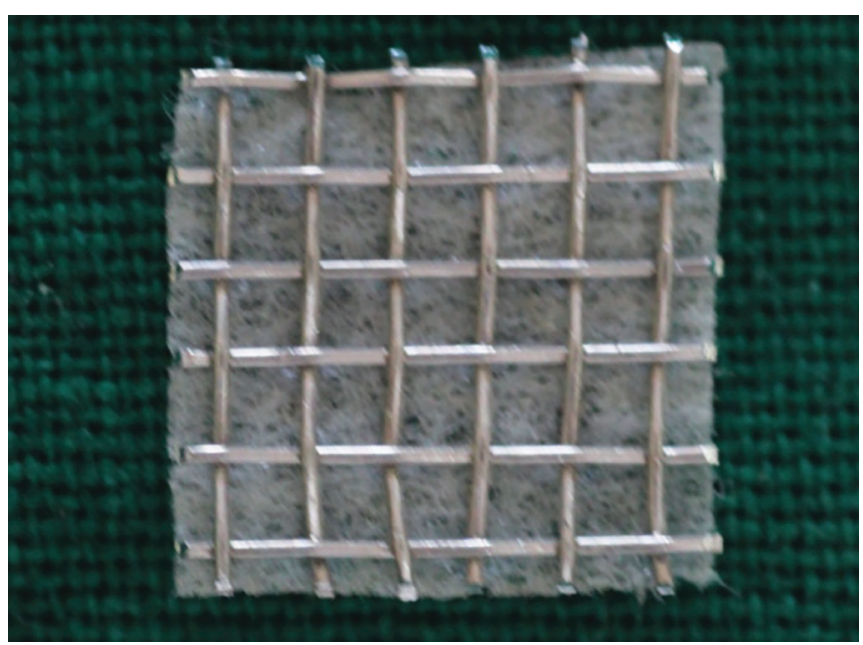

Fig. 3: Cut-out of the mesh

to be carried out using microimplants. The placement of microimplant is critically important in the interradicular area owing to the proximity of the roots. Therefore, to obtain a precise placement of the microimplant, a grid was designed. The description of the procedure is as follows.

Commercially available stainless steel wire mesh, easily procured from hardware suppliers was utilized. The mesh was selected such that the distance between the successive vertical and horizontal wire components was $2 \mathrm{~mm}$. The mesh was autoclaved (Fig. 1). The next step involved sticking the micropore surgical tape over the mesh to make small cut-outs (Fig. 2). These cut-outs were appropriately sized in $1 \mathrm{~cm} \times 1 \mathrm{~cm}$ to cover the area of interest and stored in a sterile container for use (Fig. 3). The grid can be made smaller if needed by cutting with scissors before use. After anesthetizing the area, wet cotton was used to moisten the temporary anchorage device site and also to slightly moisten surgitape for better adhesion of Trioplast dental paste (ICPA Health Products,

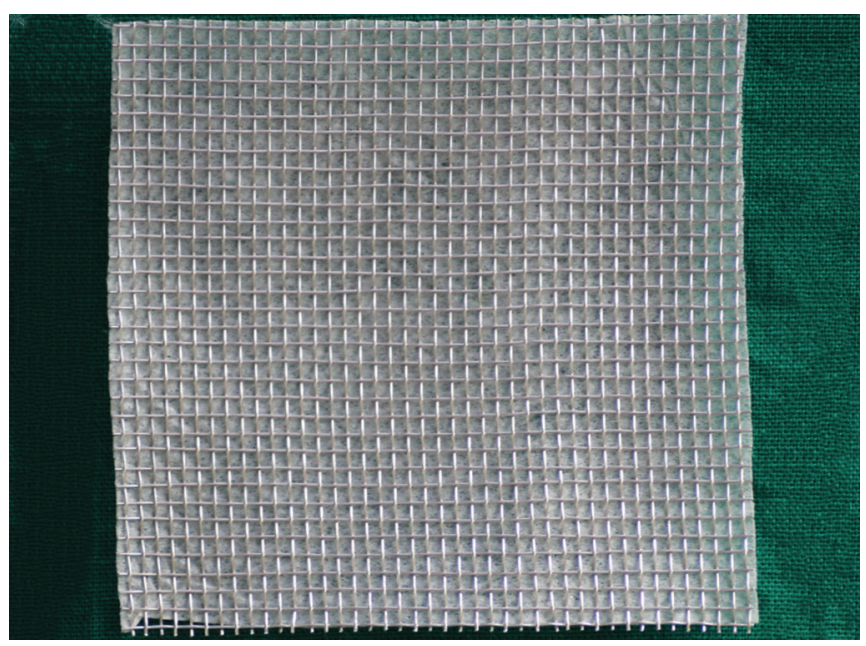

Fig. 2: Mesh with micropore surgical tape

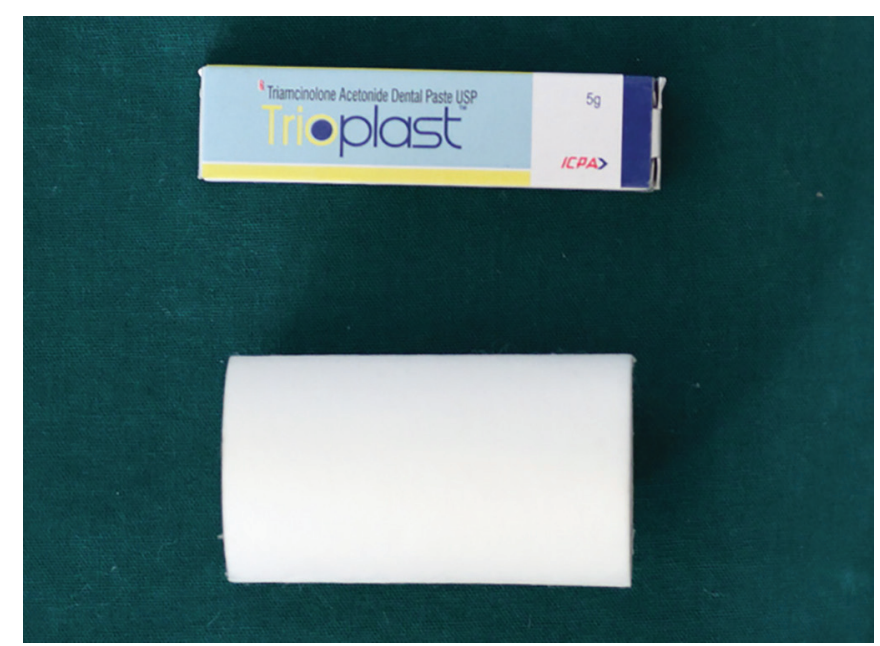

Fig. 4: Surgical tape and Trioplast dental paste
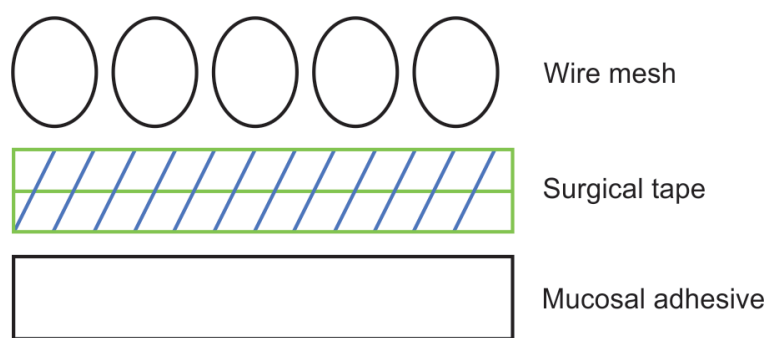

Fig. 5: Diagrammatic representation of the grid assembly

Mumbai, Maharashtra) on the grid (Fig. 4). The grid was adapted with finger pressure. A thin layer of Trioplast was applied on the tissue-facing surface of the surgitape. The paste acts as a mucosal adhesive, stabilizing the grid firmly in place. Thus, the grid assembly consists of the grid on a micropore surgical tape with ointment below the tape (Fig. 5). This assembly was then transferred in the right maxillary posterior region between the second premolar and first molar and was pressed firmly onto the mucosa (Fig. 6). This was followed by obtaining an intraoral periapical radiograph of that area. The radiograph 


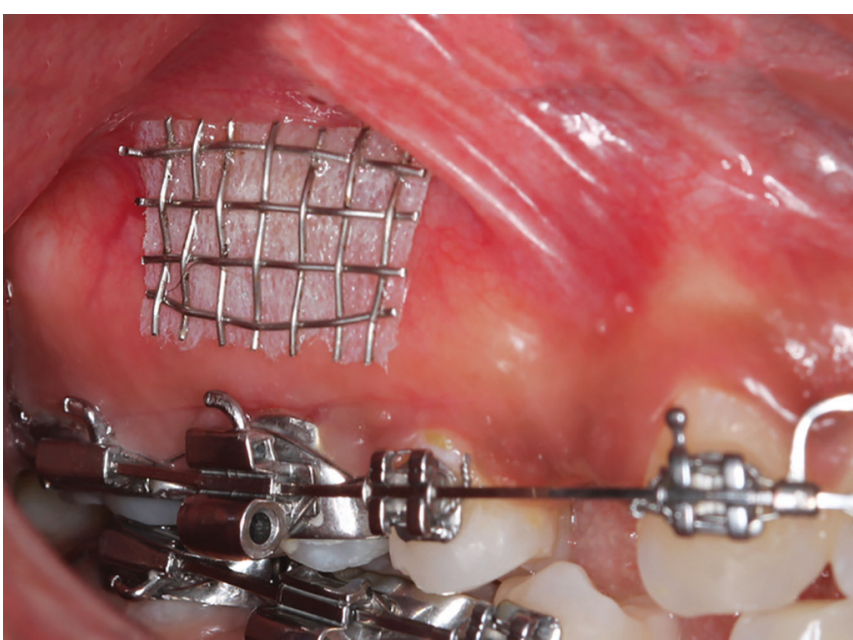

Fig. 6: Grid assembly at the intended site of placement

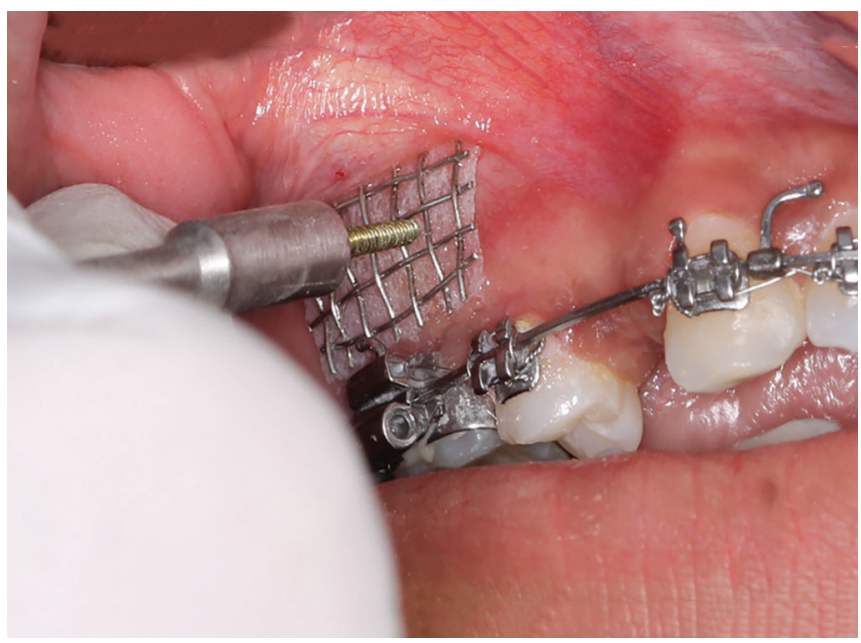

Fig. 8: Microimplant driven through the grid

showed the grid superimposed on the inter-radicular area between the second premolar and molar (Fig. 7). The appropriate square component of the guide corresponding to the exact height of placement of the microimplant

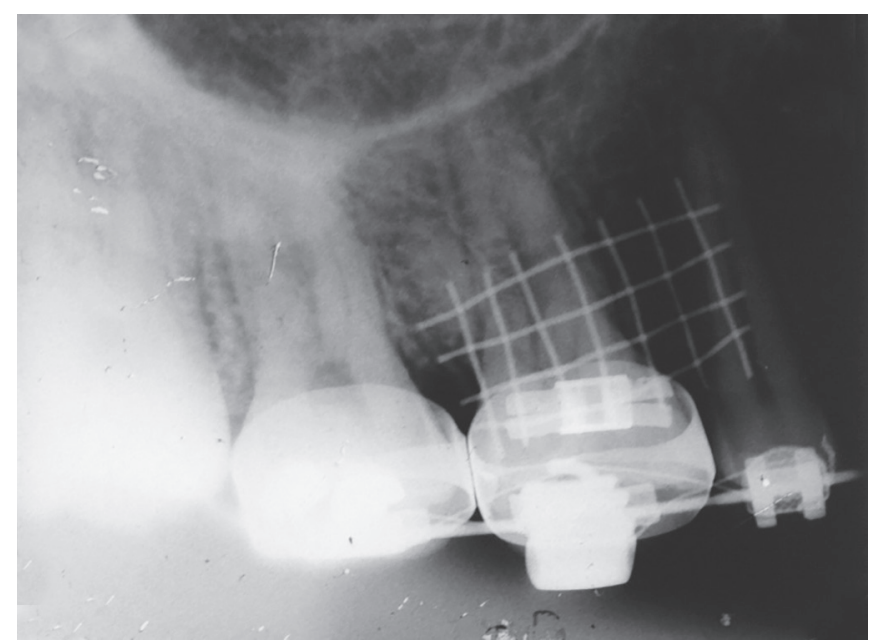

Fig. 7: Intraoral periapical radiograph of the grid at the intended site of placement

was selected on the radiograph. The microimplant was then driven through that same square on the grid (Fig. 8). After insertion of the implant, the gird was removed by cutting it off with a pin and ligature cutter. The placement and orientation of the microimplant were successful (Fig. 9).

\section{DISCUSSION}

Gainsforth and Higley ${ }^{21}$ carried out distilization of maxillary dentition using Class II elastics with anchorage from metallic vitallium screws in dog ramus. However, all screws failed within 16 to 31 days. The next set of published reports with regard to the successful use of endo-osseous implants to move teeth was given forth by Linkow..$^{22}$ He used mandibular blade-vent implants in a patient to apply Class II elastics for retraction of maxillary incisors. Creekmore and Eklund ${ }^{23}$ suggested the use of small-sized vitallium screws as anchorage for the intrusion of maxillary incisors. Kanomi ${ }^{24}$ introduced microscrews for orthodontic anchorage. He showed that
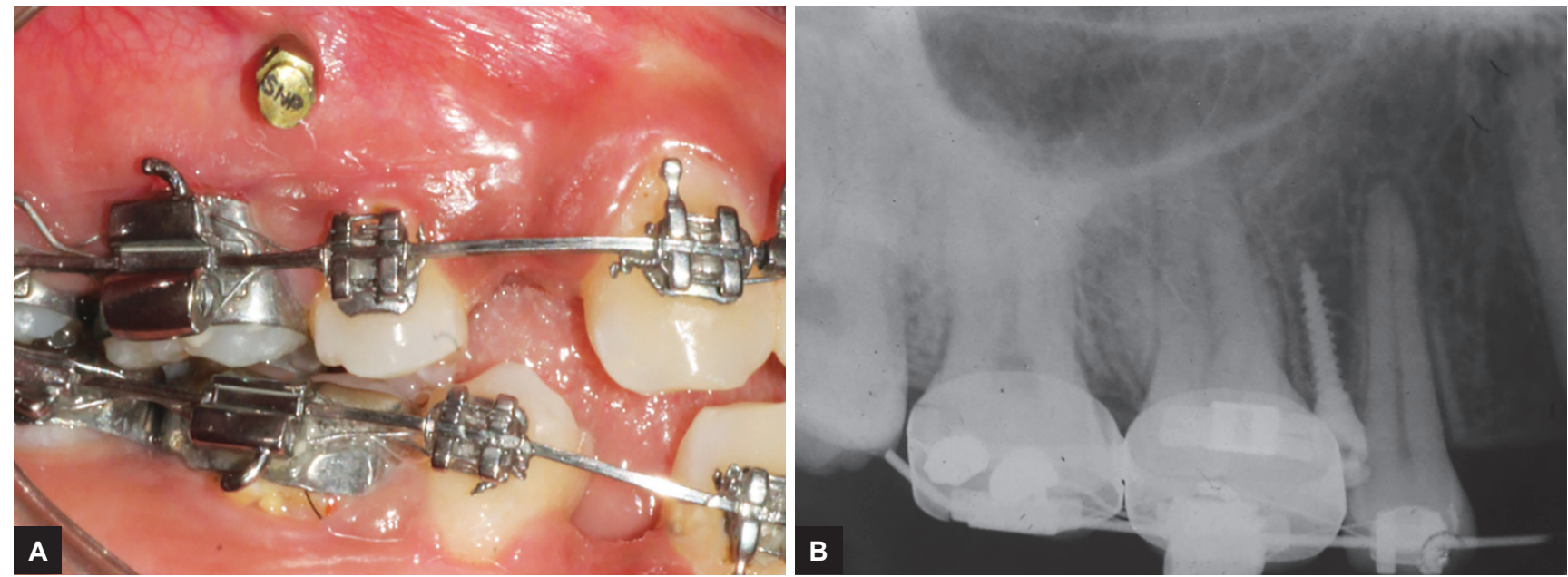

Figs 9A and B: (A) Intraoral placement of microimplant; and (B) radiographic placement of microimplant 
$1.2 \mathrm{~mm}$ diameter of microscrew is enough for intrusion of anterior teeth.

In the case of interradicular placement of implant, the structure in close approximation would be the roots of the teeth. The microimplant may contact the root thus, leading to its failure. According to Kuroda et al, ${ }^{9}$ root proximity is a risk factor in microimplant failure. Therefore, it is important to prevent root contact when placing microimplants into alveolar bone.

This particular grid design offers a variety of advantages. The mesh is easily available in the market. The squares in the gird are of dimension $2 \times 2 \mathrm{~mm}^{2}$. This selection was based on the fact that implants range in 1.4 to $2 \mathrm{~mm}$ diameter, the most common being 1.6 to $1.8 \mathrm{~mm}$ diameters. This is greater than the implant diameter, which, in turn, facilitates the placement of the implant through the gird while it is held in place. The application of surgical tape helps in holding the mesh wires in place, while cut-outs are being made. Making the cut-outs hardly requires a couple of minutes. The cut-outs can be made and stored. These can be used as and when required. Also, there are not much of technicalities to make the cut-outs, so even a dental assistant can prepare and store them. The use of surgical tape is not only for holding the wire mesh in place, but it also acts as a smooth uniform surface for adhesive placement. The material chosen was stainless steel, as it can be easily contoured according to the anatomy of the area where it is being placed. This was done to achieve an intimate contact with the area of placement. The cut-outs can be adjusted by the orthodontist as per the dimension of the placement area. The Trioplast dental paste (triamcinolone acetonide ointment in oraplast base contains gelatin $16.7 \% \mathrm{w} / \mathrm{w}$, pectin $16.7 \% \mathrm{w} / \mathrm{w}$, sodium carboxymethylcellulose $16.7 \% \mathrm{w} / \mathrm{w}$ ) is a commonly prescribed over-the-counter remedy for the oral ulcerations caused by orthodontic appliances. This paste has the advantage of being adhesive to the oral mucosa. Mucosal adhesive pastes work on the principled of dessication of the mucosa. This helps in bringing about a close adaptation of the gird assembly on to the mucosa resulting in a more precise location on the radiograph without having to worry about the magnification factor. The immediate postoperative discomfort is less because of the anti-inflammatory properties of triamcilone acetonide. There is no cumbersome laboratory work required in its fabrication. After use, it can be discarded each time a new gird is used for the patient.

\section{CONCLUSION}

This technique utilizes readily available armamentarium available in an orthodontic setup. The utilization of mucosal adhesive gave a closer and better tissue adaptation. There were no cumbersome wire bendings required.
The mesh pieces with surgitape backing can be kept in stock and Trioplast can be applied just before placement. The grid is to be discarded after use. Hence, it is a simple, cost-effective, and time-saving technique.

\section{REFERENCES}

1. Lee JS, Park HS, Kyung HM. Micro-implant anchorage for lingual treatment of a skeletal Class II malocclusion. J Clin Orthod 2001 Oct;35(10):643-647.

2. Park HS, Bae SM, Kyung HM, Sung JH. Micro-implant anchorage for treatment of skeletal Class I Bialveolar protrusion. J Clin Orthod 2001 Jul;35(7):417-422.

3. Bae SM, Park HS, Kyung HM, Kwon OW, Sung JH. Clinical application of micro-implant anchorage. J Clin Orthod 2002 May;36(5):298-302.

4. Kyung HM, Park HS, Bae SM, Sung JH, Kim IB. The lingual plain-wire system with micro-implant anchorage. J Clin Orthod 2004 Jul;38(7):388-95.

5. Park HS, Kwon OW, Sung JH. Micro-implant anchorage for forced eruption of impacted canines. J Clin Orthod 2004 May;38(5):297-302.

6. Carano A, Lonardo P, Velo S, Incorvati C. Mechanical properties of three different commercially available miniscrews for skeletal anchorage. Prog Orthod 2005 Feb;6(1):82-97.

7. Park HS, Jang BK, Kyung HM. Maxillary molar intrusion with micro-implant anchorage (MIA). Aust Orthod J 2005 Nov;21(2):129-135.

8. Choi HJ, Kim TW, Kim HW. A precise wire guide for positioning interradicular miniscrews. J Clin Orthod 2007 May;41(5):258-261.

9. Kuroda S, Yamada K, Deguchi T, Hashimoto T, Kyung HM, Takano-Yamamoto T. Root proximity is a major factor for screw failure in orthodontic anchorage. Am J Orthod Dentofacial Orthop 2007 Apr;131(4 Suppl):S68-S73.

10. Alle RS, Suma T. A simple wire guide for positioning micro implants. J Indian Orthod Soc 2010 Jan:44(1):60-61.

11. Hemanth M, Patil GS, Verma S. Micro-implant positioning guide. J Clin Orthod 2012 Jan;46(1):37-38.

12. Al-Suleiman M, Shehadah M. AUSOM: a 3D placement guide for orthodontic mini-implants. Orthodontics (Chic.) 2011 Spring;12(1):28-37.

13. Cousley RR, Parberry DJ. Surgical stents for accurate miniscrew insertion. J Clin Orthod 2006 Jul;40(7):412-417.

14. Sharma NS, Shrivastav SS, Hazarey PV, Kamble RH, Sharma PN. Universal wire grid for implant placement in three dimensions. World J Dent 2013 Jan-Mar;4(1):74-76.

15. Kravitz ND, Kusnoto B, Hohlt WF. A simplified stent for anterior miniscrew insertion. J Clin Orthod 2007 Apr;41(4): 224-226.

16. Suzuki EY, Buranastidporn B. An adjustable surgical guide for miniscrew placement. JClin Orthod 2005 Oct;39(10): 588-590.

17. Morea C, Dominquez GC, Wuo Ado V, Tortamano A. Surgical guide for optimal positioning of mini-implants. J Clin Orthod 2005 May;39(5):317-321.

18. Estelita Cavalcante Barros S, Janson G, Chiqueto K, De Freitas MR, Henriques JF, Pinzan A. A three-dimensional radiographic-surgical guide for mini-implant placement. J Clin Orthod 2006 Sep;40(9):548-554.

19. Reddy KB, Kumar MP, Kumar MN. A grid for guiding miniscrew placement. J Clin Orthod 2008 Sep;42(9):531-532. 
20. Ludwig B, Glasl B, Leitz T, Kopp S. Radiological location monitoring in skeletal anchorage: introduction of a positioning guide. J Orofac Orthop 2008 Jan;69(1):59-65.

21. Gainsforth BL, Higley LB. A study of orthodontic anchorage possibility in basal bone. Am J Orthod 1945 Aug;31(8): 406-417.
22. Linkow LI. The endosseous blade implant and its use in orthodontics. Int J Orthod 1969 Dec;7(4):149-154

23. Creekmore TD, Eklund MK. The possibility of skeletal anchorage. J Clin Orthod 1983 Apr;17(4):266-269.

24. Kanomi R. Mini-implant for orthodontic anchorage. J Clin Orthod 1997 Nov;31(11):763-767. 